\title{
A variação linguística em provas de vestibular da UECE: Uma breve análise de questões de língua portuguesa
}

\section{The variation in the vestibular tests of UECE: A brief analysis of portuguese language questions}

\author{
Vinicius da Silva Vieira \\ http://orcid.org/0000-0002-1740-3549 \\ Cassio Murilio Alves de Lavor ${ }^{2}$ \\ http://orcid.org/0000-0002-5228-6042 \\ Aluiza Alves de Araújo 3 \\ http://orcid.org/0000-0003-2166-0852
}

\begin{abstract}
Resumo: Esta pesquisa de natureza quantitativa e descritiva investiga a presença do fenômeno da variação linguística em provas da primeira e segunda fase do vestibular da Universidade Estadual do Ceará (UECE) no período de 2009.2 a 2019.1, com o objetivo de verificar se as recomendações dos PCN de linguagens e códigos, quanto à presença do fenômeno da variação e mudança linguística, vêm sendo observadas pela banca organizadora do certame. Para esse estudo, selecionamos questões de língua portuguesa que abordam o fenômeno da variação,
\end{abstract}

\footnotetext{
${ }^{1}$ Mestrando do Programa de Pós-Graduação em Linguística Aplicada da Universidade Estadual do Ceará (POSLA/UECE). E-mail: viniciusfmjs@gmail.com

${ }^{2}$ Mestre pelo Programa de Pós-Graduação em Linguística Aplicada da Universidade Estadual do Ceará (POSLA/UECE). E-mail: murilolavor_rh@hotmail.com

3 Professora Doutora do Programa de Pós-Graduação em Linguística Aplicada da Universidade Estadual do Ceará (POSLA/UECE). E-mail: aluizazinha@hotmail.com
} 
dividindo-as em dois grupos - questões categóricas e questões superficiais - para formar um corpus significativo, do qual extraímos, após acurada análise, os resultados estatísticos que nos permitem afirmar que, em um universo de 670 questões, o fenômeno ainda é pouco contemplado, fato que nos levou à conclusão de que as diretrizes dos PCN de língua portuguesa não vêm sendo seguidas pela banca examinadora que elabora o vestibular da UECE.

Palavras-chave: Vestibular da UECE; Variação linguística; PCN.

\begin{abstract}
This quantitative and descriptive research investigates the presence of the phenomenon of linguistic variation in tests of the first and second phases of the vestibular of the State University of Ceará (UECE) in the period from 2009.2 to 2019.1, with the objective of verifying if the recommendations of the PCN of languages and codes, regarding the presence of the phenomenon of variation linguistic, have been respected by the organizing bank of the event. For this study, we selected questions that address the phenomenon of variation and change, dividing them into two groups- categorical questions and superficial questions- to form a significant corpus, from which we extracted, after accurate analysis, the statistical results allow us to affirm that in a universe of 670 questions, the phenomenon is still little contemplated, a fact that led us to the conclusion that the guidelines of the Portuguese-speaking PCN are not being followed by the examining bank that prepares the UECE entrance exam.
\end{abstract}

Keywords: UECE's vestibular; Linguistic variation; PCN.

\title{
Introdução
}

A sociolinguística tem se apresentado, nas últimas décadas, como um campo de estudo altamente produtivo nas pesquisas linguísticas nacionais e contribuído positivamente para uma ampla descrição do português brasileiro. No tocante às práticas sociais que avaliam o uso da língua, podemos perceber que houve um crescente aumento, a partir da década de 80, dos processos de avaliação, usados como dispositivos de regularização dos sistemas de ensino no Brasil e como meio de inclusão e acesso dos candidatos em instituições de ensino superior, ou seja, os vestibulares de diferentes universidades e faculdades.

Posto isso, uma questão que surge e merece atenção são as propostas dos Parâmetros Curriculares Nacionais (doravante, PCN) no que diz respeito à aplicação de suas recomendações sobre o fenômeno da variação e mudança linguística nos livros didáticos, em sala de aula, e, consequentemente, nos processos avaliativos de vestibulares e do ENEM. Assim, entendemos que se faz necessária uma reflexão pertinente sobre a disposição de questões que contemplem esse fenômeno no vestibular da Universidade Estadual do Ceará (doravante, UECE).

O fato é que, a partir dos estudos de Labov, em meados dos anos 60, contemplando o caráter heterogêneo da língua e sua relação com o contexto social e cultural de produção, 
muitas pesquisas se intensificaram em uma tentativa de explicar os diversos fenômenos variacionistas existentes na língua e sua relação com os grupos de fala a que pertencem, atestando esse caráter heterogêneo da língua (BORTONI-RICARDO, 2004; GORSKI \& COELHO, 2006; BAGNO, 2007, entre outras).

Com relação à abordagem do fenômeno da variação linguística, recomendada pelos PCN, no material selecionado pelo Programa Nacional do Livro Didático (PNLD), do Ministério da Educação (MEC), autores como Faraco (2015), Bagno (2013) e Coelho (2007) consideram que a variação linguística não vem sendo devidamente trabalhada e que muitos materiais didáticos de língua portuguesa ainda apresentam o fenômeno de forma superficial, descrevendo apenas os tipos de variedade linguística básicos - a variação geográfica (ou diatópica) e a variação social (ou diastrática) -, deixando, então, a cargo da escola ensinar os estudantes como devem falar tendo como parâmetro somente a norma padrão.

A constatação desses autores nos motiva a investigar se a mesma realidade se apresenta ou não para o vestibular da UECE, isto é, averiguar se o fenômeno da variação linguística está sendo ou não avaliado em questões de provas para ingresso na UECE. Refletir sobre essa prática é deveras importante, uma vez que os PCN vão além do planejamento adequado das práticas pedagógicas e da escolha de materiais didáticos, pois visam também a uma valorização das variedades e ao respeito às diversidades regionais, culturais e políticas do país. Assim, entendemos que a melhor forma de contemplação do fenômeno da variação linguística é a sua inclusão no material didático e, consequentemente, no material usado para avaliar o nível de consciência e aprendizado desse aluno ao término do ensino médio, como é o caso do vestibular.

Ao longo do seu ciclo escolar, o aluno teve contato com as diversas formas linguísticas e pôde refletir sobre as peculiaridades inerentes à oralidade e à escrita. Nesse sentido, para os PCN, "O aluno, ao aprender novas formas linguísticas, particularmente a escrita e o padrão de oralidade mais formal orientado pela tradição gramatical, entende que todas as variedades linguísticas são legítimas e próprias da história e da cultura humana" (BRASIL, 1997, p. 82).

A questão é que, desde 1997, os PCN de linguagens e códigos reconhecem a variação linguística como inerente à língua e, quanto ao tratamento a ser atribuído às variedades linguísticas, nesse documento, salienta-se a necessidade de reconhecermos que nosso país apresenta uma unidade linguística - a língua portuguesa - que é constituída por muitas variedades, sendo que "o uso de uma ou outra forma de expressão depende, sobretudo, de fatores geográficos, socioeconômicos, de faixa etária, de gênero (sexo), da relação estabelecida entre os falantes e do contexto de fala" (BRASIL, 1997, p. 29). 
Registrados nossos questionamentos, elucidamos que o objetivo desta pesquisa é verificar a presença, ou não, do fenômeno da variação linguística nos vestibulares aplicados nos últimos dez anos pela UECE em suas provas de língua portuguesa. Analisaremos questões dos vestibulares aplicados nos semestres 2009.2 a 2019.1, especificamente aquelas que avaliam o conhecimento do aluno acerca da língua portuguesa e suas variedades e registros.

Esta pesquisa está dividida nesta introdução, que aborda a problemática e, de maneira panorâmica, os objetivos dos PCN. Em seguida, traçamos linhas gerais acerca da sociolinguística variacionista. Depois tratamos, com mais propriedade, dos PCN, para, então, apresentarmos uma breve história da UECE e de como se dá o seu vestibular. A quinta parte da pesquisa apresenta a metodologia aplicada para, posteriormente, explorarmos o corpus criado a partir da seleção das questões. Na sexta seção, analisamos e apresentamos os gráficos e tabelas relativos aos nossos resultados, para terminarmos com nossas considerações finais.

A próxima seção faz um breve resumo sobre a teoria da sociolinguística variacionista, motivação epistemológica para o nosso trabalho.

\section{A sociolinguística variacionista}

Estudos que imbricam os fatores língua e sociedade começam sua atuação nas discussões linguísticas marcadamente no início do século XX, referendados por autores como Antoine Meillet, Mikhail Bakhtin, Émile Benveniste entre outros. Segundo Calvet (2002), mesmo sendo discípulo dos postulados saussurianos, mais especificamente no que tange aos estudos diacrônicos, o linguista Meillet, por exemplo, já defendia a inseparabilidade entre história das línguas e história das culturas e sociedades. Ultrapassando a metade do referido século, os estudos sociolinguísticos começaram a tomar mais saliência e vigor. Nesse contexto, não obstante a falta de criteriosa precisão teórico-metodológica, o linguista William Bright já estabelecia a tese fundamental da impossibilidade de criar relações entre os fatores linguísticos e a estrutura social partindo-se de um sistema linguístico considerado sem o âmbito da variação (CAMACHO, 2012).

A partir da década de 60, dentre os levantamentos já feitos em torno da sociolinguística, o marco teórico que recebeu e até hoje ainda recebe a atenção por sua respaldada contribuição para os estudos linguísticos foi a sociolinguística variacionista, começando a ganharem resolução as inconsistências teórico-metodológicas anteriores. Este campo de estudo é amparado pelos postulados da Teoria da Variação e Mudança Linguística, 
instaurada por William Labov. É da competência dessa teoria mostrar e explicar os fenômenos que estão em variação na língua, evidenciando o quanto esta é dinâmica e motivada não só por fatores que lhe são intrínsecos (linguísticos), mas também externos (sociais). Assim, estudos nessa área sinalizam a estreita relação entre língua e sociedade, vínculo desconsiderado por muito tempo em meio aos estudos linguísticos.

O fator que serviu como estopim e também como força propulsora para a sociolinguística variacionista foi o rompimento com a ideia de língua enquanto sistema homogêneo e estático apregoada pelos moldes estruturalistas da linguística. Com essa ruptura, a proposta passou a ser o reconhecimento de que o âmbito da variação e mudança linguística deve ser entendido "como uma consequência inevitável da dinâmica interna das línguas naturais." (WEINREICH; LABOV; HERZOG, 2006, p. 139). Nesse sentido, para Labov, a associação entre estrutura e homogeneidade é considerada uma ilusão, uma vez que a natureza heterogênea da língua é altamente passível de ser sistematizada, a partir do axioma laboviano da heterogeneidade ordenada (WEINREICH; LABOV; HERZOG, 2006).

Nesse ínterim, é fundamental à competência linguístico-comunicativa de um falante o conhecimento das formas como se manifesta a variação, a saber: a geográfica (ou diatópica), que nos permite reconhecer a origem de um indivíduo pela maneira como este fala; a social (ou diastrática), que ocorre sob a influência de fatores como escolaridade, nível socioeconômico, ocupação; a diageracional, que envolve os condicionamentos etários; a diagenérica, que respeita aos papéis sociais associados ao gênero/sexo; a estilística ou diafásica, decorrente dos papéis sociais desempenhados pelas pessoas na rotina social; e a diamésica, concernente ao caráter variável entre as modalidades oral e escrita. Portanto, o conhecimento dessas formas de variação deve gerar a compreensão no falante de que, ligado ao caráter estrutural da língua, existe também seu importante aspecto heterogêneo, o qual não implica desordem, mas variação motivada e sistematizada (LABOV, 2008).

Na próxima seção, apresentamos os PCN, que estão associados aos objetivos desta pesquisa.

\section{Os PCN de linguagens e códigos}

Os PCN foram criados em 1996, postos em circulação a partir de 1998, e tratam-se de um trabalho minucioso que propõe uma reflexão sobre as práticas pedagógicas docentes, favorecendo um planejamento da seleção dos conteúdos didáticos a serem trabalhados. Esse 
documento indica também as práticas em sala de aula a partir de orientações quanto às ferramentas a serem utilizadas para se obter um melhor resultado na formação do alunado e no seu desenvolvimento profissional, tendo em vista o respeito às diversidades regionais, culturais e políticas do país. Isso nos leva a afirmar que a prioridade dos PCN está, no âmbito linguístico, entendida a partir da variação linguística concernente a cada região do país, haja vista essas diretrizes curriculares proporem valorizar as variedades, além de ressaltarem a diferença entre língua escrita e língua oral. Para os PCN, ainda, "a imagem de uma língua única, mais próxima da modalidade escrita da linguagem, não se sustenta na análise empírica dos usos da língua" (BRASIL, 1997, p. 29).

Assim, os PCN, criados em função da LDB 9.394/96 (Lei de Diretrizes e Bases da Educação), consistem em documentos que compõem e indicam a grade curricular das instituições educativas, elaborados com o propósito de nortear o trabalho docente e as atividades a serem realizadas na sala de aula. Os PCN contêm também orientações quanto ao cotidiano escolar e aos principais conteúdos que devem ser trabalhados, subsidiando os educadores para que suas práticas pedagógicas sejam eficazes e significativas.

É preciso esclarecer que cada instituição deve montar o seu Projeto Político Pedagógico, isto é, sua proposta pedagógica, adaptando os conteúdos norteados à realidade social da localidade onde está inserida.

Quanto às diretrizes destinadas a área de linguagem, os PCN orientam que

\begin{abstract}
a questão não é falar certo ou errado, mas saber qual forma de fala utilizar, considerando as características do contexto de comunicação, ou seja, saber adequar o registro às diferentes situações comunicativas [...]. É saber, portanto, quais variedades e registro da língua oral são pertinentes em função da intenção comunicativa, do contexto e dos interlocutores a quem o texto se dirige. (BRASIL, 1997, p. 31).
\end{abstract}

Enquanto fenômeno inserido nesses diferentes contextos comunicativos, os PCN trazem especificações atinentes à variação linguística, esclarecendo a importância de o aluno aprender, além da escrita e o padrão da oralidade formal, novas formas linguísticas, entendendo que "todas as variedades linguísticas são legítimas e próprias da história e da cultura humana" (BRASIL, 1997, p. 82). Considerada tal importância, os PCN apresentam algumas atividades em seu texto que permitem explorar mais profundamente a variação linguística, como as seguintes: transcrever textos orais, de modo a identificar recursos linguísticos pertencentes à fala; editar textos orais em gêneros escritos a fim de perceber distinções entre fala e escrita; analisar a 
expressividade da linguagem popular em gêneros textuais da comunicação cotidiana; levantar marcas de variação linguística por meio da comparação de textos de diferentes gêneros com um mesmo assunto para diferentes públicos.

Entendemos, com base nas atividades elencadas, que, para os PCN, as práticas educacionais têm o dever de valorizar uma educação social, democrática e contemplativa das diferenças culturais dos educandos, proporcionando-lhes o acesso real aos saberes linguísticos e visando ao exercício da cidadania, direito inalienável do ser humano. Dessa forma, tais diretrizes educacionais contemplam a visão variacionista da língua em seu texto, reconhecendoa como algo inerente à língua e entendendo-a como um fenômeno associado a valores sociais e que cabe ao professor e à escola cuidar para que não ocorra, tampouco seja reproduzido, o preconceito linguístico. Percebemos, então, que esse documento educacional, indo ao encontro dos princípios da sociolinguística variacionista, contrapõe-se a um modelo de ensino de língua portuguesa baseada apenas em regras impostas pela gramática prescritiva, que toma como "errada" a variação linguística que se diferencia da norma culta.

Os parâmetros indicam, ainda, que deve existir autonomia, por parte dos alunos, no ato de leitura textual de assuntos com os quais eles têm familiaridade e, também, de gêneros diferentes, articulando-os o máximo possível com outros textos; assim, realiza-se a promoção da intertextualidade, em que, além de confrontar-se com textos diversos, o aluno se utiliza de seu conhecimento de mundo para dar significado às expressões não usuais, aumentando seu repertório linguístico. Entendemos que, em relação a esse ponto, os manuais abordam, implicitamente, a questão da variação linguística.

Com relação ao processo de produção dos textos orais, a utilização e a valorização do repertório linguístico da comunidade do aluno é, mais uma vez, apontada pelos PCN. Estes ressaltam, no processo de análise linguística, as variedades linguísticas ganhando espaço na gramática, ao indicar que o aluno: apreenda conhecimentos sobre o funcionamento e o sistema linguístico relevantes para escuta, leitura e produção de textos; utilize-se dos instrumentos de natureza procedimental e conceitual necessários à análise e reflexão linguísticas; verifique as diferentes variedades da língua portuguesa, observando preconceitos entre formas populares e grupos sociais favorecidos. Podemos depreender, então, a atenção do referido documento à importância da variação linguística no ensino de língua portuguesa.

Tendo delineado o norte proposto pelos PCN às instâncias que envolvem a variação linguística no ensino de português, apresentamos, brevemente, na próxima seção, aspectos históricos e institucionais da UECE, bem como descrevemos a sua forma de ingresso, ou seja, o vestibular, explicando os procedimentos avaliativos e o progresso dessa instituição ao longo dos 
anos para tornar-se uma das universidades mais recomendadas do estado do Ceará e do país.

\section{UECE: histórico, institucional e forma de ingresso}

Uma das instituições de referência no Ensino Superior do Ceará é a Universidade Estadual do Ceará (UECE), cuja história começou ancorada na lei nº 9.753 de 18 de outubro de 1973, que decretou autorização para que fosse implementada a Fundação Educacional do Estado do Ceará (FUNEDUCE), atual Fundação Universidade Estadual do Ceará (FUNECE). À época, era notória a necessidade de um aumento na qualidade de vida da população cearense, daí a missão da referida fundação estar diretamente ligada à formação de profissionais por meio da produção e propagação do conhecimento. Contudo, foi somente a 5 de março de 1975 que foi criada a Universidade Estadual do Ceará, sob autorização da resolução número 2 do Conselho Diretor e ratificada pelo Decreto $\mathrm{n}^{\circ} 11.233$, de 10 de março do mesmo ano.

Apenas em 1977, a UECE estava mais solidificada em suas instalações, responsabilizando-se por formar profissionais para os âmbitos sociais mais necessários, como Ciências da Saúde (Enfermagem e Nutrição); Ciências Tecnológicas (Matemática, Física, Química, Ciências Puras, Geografia e Ciências da Computação); Ciências Sociais (Administração, Ciências Contábeis, Serviço Social e Pedagogia); Ciências Humanas (Letras, Filosofia, História, Música, Instrumento-Piano e Estudos Sociais); e Ciências Agrárias (Medicina Veterinária).

Com o passar dos anos, a FUNECE/UECE veio atingindo patamares mais altos, pois além de aprimorar seu foco primeiro - educação e formação de professores - voltou-se também para o desenvolvimento científico e tecnológico, altamente requerido pelo estado do Ceará. Assim, com várias faculdades e centros, indo além da capital Fortaleza e passando a atuar em outros municípios cearenses (Crato, Tauá, Juazeiro do Norte, Iguatu, Limoeiro do Norte, Quixadá, Ipu, Crateús, Ubajara, Itapipoca, Redenção e Cedro), a UECE configura-se como uma instituição multicampi. Tal configuração assinala a importância dessa Universidade mediante as múltiplas demandas socioprofissionais do estado cearense, comprometendo-se com a formação de profissionais para atendê-las proficuamente.

Apresentados concisamente alguns aspectos históricos e institucionais da UECE, partimos para a descrição de um ponto que muito importa ao nosso estudo: o ingresso dos alunos na UECE. Como em muitas outras IES, a referida instituição dispõe de diferentes tipos de seleção para ingressantes, como o vestibular tradicional (para cursos presenciais), o vestibular a distância (para cursos EAD) e a seleção para alunos transferidos (interna e externamente) e 
graduados. A título de informação, salientamos que a UECE utiliza as notas do ENEM para distribuição, entre os candidatos interessados, de vagas remanescentes do vestibular tradicional, após a realização do mesmo. Para o presente estudo, deter-nos-emos no vestibular tradicional, uma vez que é a forma mais substantiva de ingresso na instituição.

O vestibular tradicional da UECE ocorre duas vezes por ano e é composto por duas fases. Com base em CEV4/UECE (2019), a primeira fase do certame, de caráter geral, atualmente é constituída por 80 questões objetivas (de múltipla escolha, alternativas ABCD) de conhecimentos gerais, divididas entre as seguintes disciplinas da educação básica: língua portuguesa (12 questões), matemática (10 questões), língua estrangeira5 (8 questões), história (8 questões), geografia (8 questões), biologia (8 questões), química (8 questões), física (8 questões), filosofia (5 questões) e sociologia (5 questões); essa fase6 ocorre em um único dia, com duração de quatro horas.

Quanto à segunda fase, esta é composta por uma prova de redação em língua portuguesa e por três provas de conhecimentos específicos também de múltipla escolha (ABCD) com 20 questões cada, totalizando 60 questões. A prova de redação é para todos os candidatos habilitados para a segunda fase, e as específicas são feitas de acordo com o curso para o qual o candidato esteja pleiteando vaga. Por exemplo, um candidato, inscrito no vestibular, que queira ingressar no curso de Letras-Português, além da redação, fará provas de língua portuguesa, história e geografia.

Para atender aos objetivos de nossa análise, interessou-nos apenas as questões das provas de língua portuguesa, que eram em número de 34 por vestibular (14 na primeira fase e 20 na segunda); esse número caiu para 32 questões, uma vez que a prova de língua portuguesa da $1^{\text {a }}$ fase passou a ter 12 questões, devido à mudança na distribuição de questões da prova de conhecimentos gerais a partir do vestibular de 2017.1, conforme tomamos nota anteriormente.

Tendo como foco essas questões, fizemos uma leitura do programa de estudos de língua portuguesa disponível nos editais aos candidatos. No referido programa, CEV/UECE

\footnotetext{
4 Comissão Executiva do Vestibular da Universidade Estadual do Ceará (UECE).

5 O candidato pode escolher entre inglês, espanhol e francês.

${ }^{6} \mathrm{~A}$ partir da coleta das provas, percebemos que, até os vestibulares do ano de 2016, a prova de conhecimentos gerais era composta por 60 questões (14 de língua portuguesa, 10 de matemática, 6 de história, 6 de geografia, 6 de biologia, 6 de química, 6 de física e 6 de língua estrangeira). A partir de 2017, essa prova passou a ter 70 questões, com uma redistribuição diferente (12 de língua portuguesa, 10 de matemática, 8 de história, 8 de geografia, 8 de biologia, 8 de química, 8 de física e 8 de língua estrangeira). Recentemente, a partir do vestibular 2019.1, a mesma prova passou a ser composta por 80 questões, devido ao acréscimo das disciplinas de filosofia e sociologia (5 questões para cada), o que vigora atualmente.
} 
(2018, p. 29) considera "como objetivo principal do ensino de Língua Portuguesa o desenvolvimento da competência discursiva" e avalia os candidatos no que concerne à habilidade de compreensão e produção de textos, bem como em relação ao domínio de conhecimentos gramatical-discursivos que, segundo a banca examinadora do vestibular, subsidiam a referida habilidade. Para atingir esse objetivo em sua forma de avaliar, CEV/UECE (2018) propõe um programa de língua portuguesa que abrange três instâncias: aspectos textuais (fatores de coerência, elementos de coesão, co(n)texto, gênero, composição, propósito, recursos expressivos da linguagem e variação linguística); aspectos gramaticais e gráficos (estrutura, formação e classificação de vocábulos, estrutura e constituintes da frase, processos de coordenação e subordinação, sintaxe de concordância, regência e colocação, convenções ortográficas da norma padrão e pontuação); e literatura (o texto literário, noções de teoria e estilística literária, escolas literárias brasileiras).

Como podemos notar, o âmbito da variação linguística é contemplado no programa de conteúdos, estando em meio aos aspectos textuais que possam vir a ser cobrados dos candidatos no certame. Salientamos que, em cada tópico de conteúdo das três instâncias, há ainda afunilamento de conteúdos, a fim de que o candidato se norteie bem no seu estudo preparatório para o vestibular. O tópico de variação linguística, pertencente à primeira instância, apresenta o seguinte afunilamento: variação dialetal - geográfica, social, temporal ou histórica - e de registro (diferentes graus de formalidade, modalidade oral ou escrita).

Tendo-nos deparado com as especificidades das provas do vestibular da UECE, mais especificamente as de língua portuguesa, descrevendo-as, expomos, na próxima seção, o traçado metodológico que aponta para o nosso objetivo.

\section{Metodologia}

Aqui, apresentamos a metodologia e entendemos que nosso estudo é de caráter quantitativo, pois "a pesquisa quantitativa recorre à linguagem matemática para descrever as causas de um fenômeno [...]" (FONSECA, 2002, p. 20), e descritivo, uma vez que esta pesquisa descreve os fatos e fenômenos de determinada realidade (TRIVIÑOS, 1987).

Para a realização dessa pesquisa, procuramos selecionar o maior número de ocorrências do fenômeno da variação linguística em questões das provas de língua portuguesa da UECE, com o objetivo de formar uma amostra capaz de fornecer subsídios na construção de nossas análises. Para isso, colecionamos, primeiramente, as provas dos vestibulares presenciais (primeira e segunda fases) dos últimos dez anos, aplicadas pela instituição no período dos 
semestres 2009.2 a 2019.1, o que nos rendeu um total de 40 provas. Realizamos um estudo de cada uma dessas provas individualmente, objetivando localizar questões que abordassem o fenômeno da variação linguística, de forma a contemplar as recomendações dos PCN quanto ao seu ensino no Brasil, para que, em seguida, pudéssemos quantificá-las.

Conforme dito anteriormente, o processo avaliativo da UECE é composto de duas fases, com perspectivas e número de questões diferentes. Dos semestres 2009.2 a 2016.2, a prova da primeira fase continha catorze questões de língua portuguesa, e a da segunda, vinte questões. De 2017.1 até o momento vigente, devido à mudança na distribuição de questões prevista em edital, a primeira fase passou a conter doze questões de língua portuguesa na primeira fase, ou seja, duas a menos. Isso nos oferece, dentro do decênio recortado, um universo de 670 questões em um total de 40 provas.

Feita a quantificação, realizamos uma seleção minuciosa de todas as questões que tratam da variação linguística de forma categórica7, ou seja, questões8 que trazem, em seu texto, enunciado, descritor e distratores, esse conteúdo, de maneira a não deixar dúvidas quanto à natureza do assunto da questão; a figura 1, a seguir, retirada de nossa amostra9, apresenta um exemplo de questão categórica.

\footnotetext{
${ }^{7}$ Durante toda a pesquisa, adotaremos esse termo para as questões que compõem no seu cerne o fenômeno da variação linguística.

${ }^{8}$ Cada questão, nos vestibulares da UECE, apresenta um descritor e três distratores, fato que evita a indução ao erro por parte do aluno.

${ }^{9}$ As figuras de nossa amostra foram extraídas das provas em formato PDF (disponíveis ao público no endereço eletrônico <http://www.uece.br/cev/ $>$, na aba Vestibulares Anteriores) por meio da ferramenta de captura do Windows, não havendo, portanto, interveniências de direito autoral sobre elas.
} 
Figura 1 - Questão 14 da prova de língua portuguesa do vestibular 2009.2 da UECE (primeira fase)

14.

No texto 2, estão presentes traços linguísticos em desacordo com 0 padrão estabelecido pela gramática normativa. Assinale a opção em que um desses traços se revela na sintaxe.

A) "Cearense não vai em festa... ele cai na gandaia!" (linhas 84-85)

B) "Cearense não bebe um drink... ele toma uma!" (linha 88)

C) "Cearense não vigia as coisas... ele pastora!" (linha 95)

D) "Cearense não é homem... ele é macho ou é cabra danado!" (linhas 101-102)

Fonte: Vestibular 2009.2 UECE, $1^{\text {a }}$ fase, p.5, jun. 2009.

Como podemos observar, a questão 14 da figura 1 contempla integralmente o fenômeno da variação linguística no Brasil. A partir do texto "O jeito cearense de ser único"10 do autor Zé Carioca, disposto como o texto-base da questão, podemos perceber que a banca elaboradora apresenta uma discussão acerca da língua padrão e a variação linguística na fala do cearense. Esse tipo de questão não deixa dúvidas quanto ao caráter do assunto abordado, pois apresenta, em seu enunciado, distratores ${ }^{11}$ e descritor ${ }^{12}$ (alternativa A), o fenômeno da variação linguística.

Selecionamos, também, questões que contemplam o fenômeno apenas de forma superficial $^{13}$, ou seja, no texto ou nos distratores, mesmo não o explorando de forma completa como uma questão categórica. A figura 2 que segue mostra um exemplo de questão superficial, retirada de nossa amostra.

\footnotetext{
${ }^{10}$ Disponível em:< www.nordesterural.com.br>. Acesso em: 19 set. 2019.

${ }^{11}$ Os distratores correspondem às alternativas que não configuram resposta para a questão.

${ }^{12} \mathrm{O}$ descritor é alternativa que equivale à resposta da questão.

${ }^{13}$ Ao longo do texto, adotaremos esse termo para as questões que contemplam o fenômeno da variação, mas não o apresentam no item descritor.
} 
Figura 2 - Questão 04 da prova de língua portuguesa do vestibular 2015.1 da UECE (segunda fase)

04. O primeiro enunciado do texto "Não, nunca me acontecem milagres" (linha 1) tem algumas peculiaridades. Assinale a alternativa correta em relação a esse enunciado.

A) O emprego do advérbio "não" no início do enunciado é textualmente irrelevante. Ele poderia ocupar qualquer lugar no enunciado sem que houvesse alteração em nenhum nível do texto.

B) Há nele uma dupla negativa, muito característica da língua popular, mas só na modalidade escrita.

C) Reescrito, o enunciado poderia ficar assim: Não me acontecem milagres nunca. Dessa maneira, efetua-se a separação dos dois elementos negativos. Essa nova estrutura prejudica a compreensão das ideias do texto.

D) Na reescritura - Não, milagres nunca me acontecem - , o sujeito do enunciado ocupa a posição canônica, isto é, a mais usada. Essa mudança altera a expressividade e a impressividade da frase.

Fonte: Vestibular 2015.1 da UECE, 2 ${ }^{\text {a }}$ fase, p.3, jun. 2015.

A figura 2 mostra uma questão que, mesmo não buscando testar os conhecimentos do aluno acerca do fenômeno da variação linguística de forma categórica, apresenta, em um de seus distratores (item B), uma consideração sobre a variação linguística referente ao fenômeno das duplas negativas. O gabarito da questão (descritor) é o item D, o qual não tem nenhuma aproximação com o distrator B. Portanto, concluímos que o item B não leva o aluno ao erro, mas o faz refletir sobre a concepção de língua popular e modalidade escrita marcada por uma língua padrão.

Assim, em uma primeira demonstração dos resultados, contemplamos apenas as questões que apresentam o fenômeno na íntegra, como demonstrado na figura 1, e, em uma segunda análise, as questões que trazem o fenômeno de forma superficial, como na figura 2, somadas às questões que apresentam o fenômeno da variação de maneira categórica.

Justificamos esse método de seleção por entendermos que, se uma questão apresenta material que contempla a variação linguística em seu texto-base ou em seu enunciado, ou ainda em seus distratores, houve uma escolha pensada, por parte da banca organizadora, para levar o aluno a ter contato com o fenômeno e chegar a uma resposta correta, a partir de suas competências e habilidades. 
Ao selecionarmos questões que contemplam o fenômeno da variação de maneira categórica ou parcial para formar o corpus deste estudo, estamos considerando que tal fenômeno pode ser explorado em um exame avaliativo de formas diferentes, e nem por isso menos importante, pois o fato de o fenômeno variacionista estar presente, independentemente de estar em um texto, enunciado ou distratores, demonstra que os organizadores tiveram o cuidado em escolher uma ferramenta que possibilite ao aluno deparar-se com a ocorrência de formas variantes na língua, ou seja, com "diversas maneiras de se dizer a mesma coisa em um mesmo contexto, e com o mesmo valor de verdade" (TARALLO, 2007, p. 8).

Na próxima seção, apresentamos a amostra analisada nesta pesquisa.

\section{Amostra da pesquisa}

Nossa amostra foi constituída por todas as questões selecionadas nas provas de língua portuguesa de primeira e segunda fases dos vestibulares da UECE ocorridos no período de 2009.2 a 2019.1, a partir de um método de triagem e escolha de questões que levou em consideração se elas contemplam o fenômeno variacionista na íntegra ou parcialmente.

Entendemos que esse tipo de método poderia nos levar a encontrar um maior número de ocorrências de questões que abarcam o fenômeno da variação linguística e, com isso, possibilitar melhores reflexões sobre o objeto de estudo. De um total de 40 provas (14 ou 12 questões na primeira fase e 20 questões na segunda), obtivemos 670 questões e, assim, conseguimos montar um corpus com 18 questões, sendo que, dentre estas, 7 apresentam o fenômeno da variação de forma categórica, e 11 questões o apresentam de forma superficial (nos textos, enunciados ou descritores). A seguir, apresentamos a tabela 1, contendo todas as questões selecionadas para nossa amostra em cada vestibular do período em análise. 
Tabela 1- Questões selecionadas das provas da UECE

\begin{tabular}{|c|c|c|}
\hline & Questões categóricas & Questões superficiais \\
\hline $\begin{array}{c}\text { Número } \\
\text { da } \\
\text { questão } \\
\text { por ano }\end{array}$ & $\begin{array}{l}\text { Questão } 14 \text { (2009.2, fase 1); } \\
\text { Questão } 15 \text { (2012.2, fase 2); } \\
\text { Questão } 02 \text { (2018.1, fase 1); } \\
\text { Questão } 17 \text { (2018.1, fase 2); } \\
\text { Questão } 19 \text { (2018.1, fase 2); } \\
\text { Questão } 20 \text { (2018.1, fase 2); } \\
\text { Questão } 05 \text { (2019.1, fase 1). }\end{array}$ & $\begin{array}{l}\text { Questão } 13 \text { (2011.2, fase 1); } \\
\text { Questão } 01 \text { (2012.1, fase 1); } \\
\text { Questão } 07 \text { (2012.2, fase 1); } \\
\text { Questão } 04 \text { (2015.1, fase 2); } \\
\text { Questão } 09 \text { (2015.2, fase 1); } \\
\text { Questão } 14 \text { (2015.2, fase 1); } \\
\text { Questão } 03 \text { (2018.1, fase 1); } \\
\text { Questão } 03 \text { (2018.1, fase 2); } \\
\text { Questão } 07 \text { (2018.1, fase 2); } \\
\text { Questão } 02 \text { (2018.1, fase 1); } \\
\text { Questão } 03 \text { (2019.1, fase 2). }\end{array}$ \\
\hline $\begin{array}{l}\text { Total de } \\
\text { questões }\end{array}$ & 07 questões & 11 questões \\
\hline
\end{tabular}

Fonte: elaborada pelos autores.

A tabela1 permite-nos uma visualização geral da disposição das questões na primeira e segunda fase do vestibular, onde notamos que a presença do fenômeno variacionista em provas de língua portuguesa do vestibular da UECE no período de 2009.2 a 2019.1 se dá em maior número nas questões superficiais em comparação às categóricas, fato que justifica nossa escolha em selecionar os dois tipos de questões, haja vista a quantidade de questões de cunho variacionista de forma categórica ser reduzida em um universo de 670 questões.

Na próxima seção, analisaremos os gráficos demonstrativos do percentual de incidência das questões de natureza variacionista nos vestibulares da UECE.

\section{Análise dos resultados}

Como já mencionamos, no período dos semestres 2009.2 e 2019.1, foram aplicadas 40 provas de vestibulares da UECE, sendo que 20 são provas de primeira fase, e 20, de segunda. 
Em um total de 670 questões selecionadas, obtivemos um total de 18 questões que contemplam o fenômeno da variação linguística no Brasil: 7 questões categóricas e 11 questões superficiais. O gráfico 1 ilustra, percentualmente, a constatação das questões categóricas.

Gráfico 1 - Questões categóricas que contemplam variação linguística nas provas de vestibular da UECE de primeira e segunda fase de 2009.2 a 2019.1

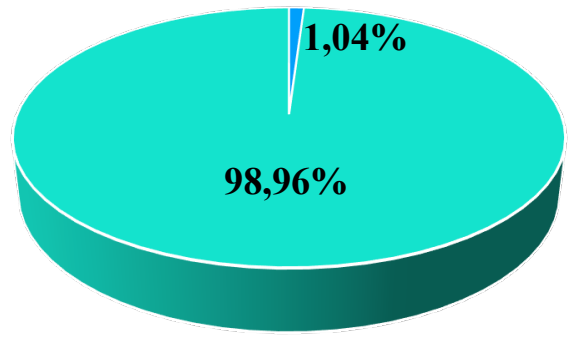

- Abordagem categórica

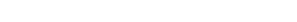

- Outras abordagens

Fonte: elaborado pelos autores.

O gráfico 1 expõe a variação linguística no vestibular da UECE, onde podemos observar que apenas $1,04 \%$ das questões tratam do fenômeno da variação linguística categoricamente. Esse resultado nos permite inferir que o número de questões que contemplam tal fenômeno ainda é muito baixo em relação às questões que abordam outros fenômenos gramaticais. Um número tão reduzido de questões variacionistas pode ser um indicativo de que o vestibular da UECE está enquadrado no modelo tradicional que prioriza a gramática normativa.

Um fato observado, na seleção das questões, foi que os textos-base ${ }^{14}$ oferecidos pela banca avaliadora são retirados dos cânones literários de autores renomados em obras que usam, prioritariamente, uma linguagem culta, como as de Lígia Fagundes Teles (2009.2, fase 2, p. 6), Manoel Bandeira (2009.2, fase 2, p. 10), Olavo Drummond (2010.1, fase 1, p. 3), Moacir Scliar (2010.1, fase 2, p. 6), Rachel de Queiroz (2010.2, fase 1, p. 3), Clarice Lispector (2010.2, fase

\footnotetext{
14 As provas com os textos-base mencionados estão disponíveis no site da Comissão Executiva do Vestibular (CEV), na aba Vestibulares Anteriores: <http://www.uece.br/cev/>, acesso em: 19 set. 2019.
} 
2, p. 6), Rubem Braga (2011.2, fase 1, p. 4), Moreira Campos (2011.1, fase 2, p. 6), Carlos Drummond de Andrade (2011.2, fase 1, p. 3), Adélia Prado (2011.2, fase 2, p. 6), Cecília Meireles (2011.2, fase 2, p. 6), Cora Coralina (2012.1, fase 1, p. 3), Graciliano Ramos (2012.1, fase 2, p. 3), Mário de Andrade (2012.2, fase 1, p. 4), Jorge Amado (2012.2, fase 1, p. 4), Chico Buarque (2012.2, fase 2, p. 8), Gilberto Freire (2013.1, fase 1, p. 2), José Américo de Almeida (2013.1, fase 1, p. 3), entre outros. Essa observação comprova o argumento de Votre (2003), o qual aponta que as formas linguísticas de prestígio na sociedade são advindas da literatura oficial, que as torna em língua padrão. Ainda nesse âmbito, observamos, também, que, diferentemente do ENEM, os vestibulares da instituição sob análise não apresentaram nenhuma charge, quadrinhos e outros gêneros de texto com transcrição da linguagem coloquial das personagens, com exceção do texto de Cora Coralina (2012.1, fase 1, p. 3), apresentado na figura 3 a seguir.

Figura 3 - Texto 1 da prova de língua portuguesa do vestibular 2012.1 da UECE (primeira fase)

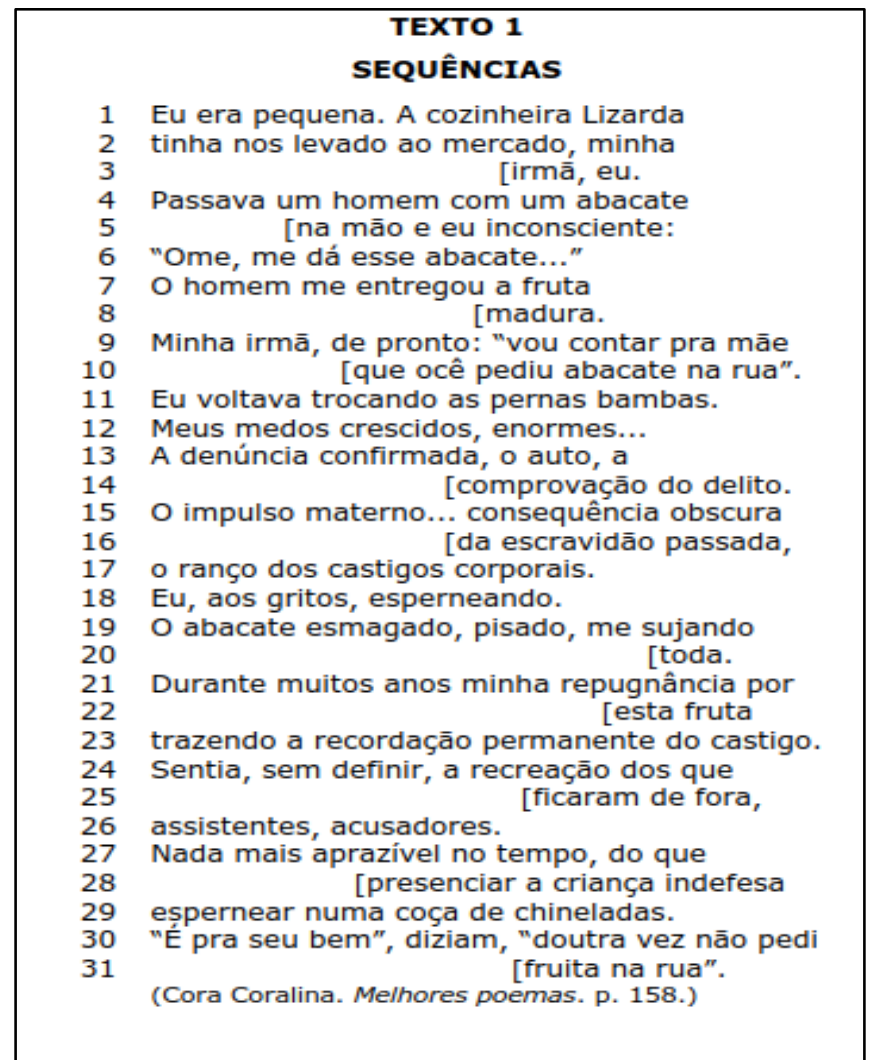

Fonte: Vestibular 2012.1 da UECE, $1^{\text {a }}$ fase, p. 3, nov. 2011. 
Como podemos perceber, o texto-base do vestibular 2012.1 da UECE (primeira fase) apresenta, em sua composição, a transcrição de uma fala marcada pela oralidade coloquial, como nos trechos "ome, me dá esse abacate..." (linha 6), "vou contar pra mãe que ocê pediu abacate na rua" (linhas 9 e 10) e "É pra seu bem" (linha 30). Em certo sentido, o texto da questão com algumas marcas coloquiais nos indica uma atenção, ainda que pequena, da banca que elaborou a prova quanto à necessidade de o aluno deparar-se com a variação linguística na prova do vestibular.

A seguir, no gráfico 2, explanamos os resultados para a quantidade de questões categóricas somadas às questões superficiais, contemplando o fenômeno da variação.

Gráfico 2 - Questões categóricas e superficiais que contemplam variação linguística nas provas da UECE de primeira e segunda fase de 2009.2 a 2019.1

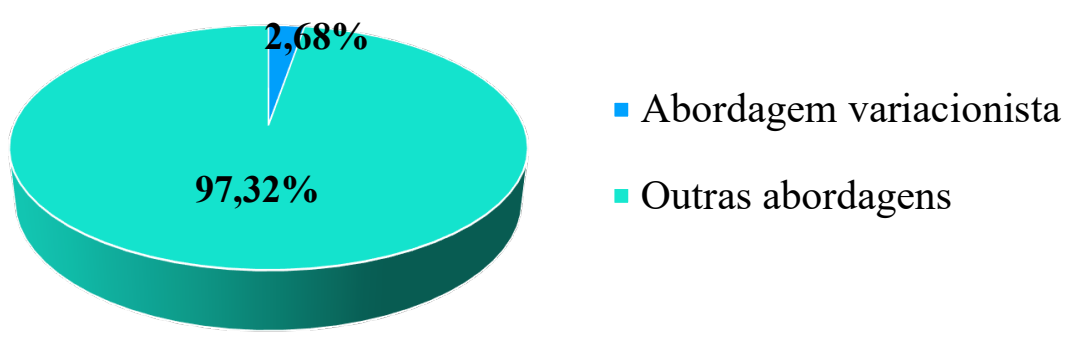

Fonte: elaborado pelos autores.

O gráfico 2 expõe a quantidade percentual quando somamos as questões de cunho variacionista categóricas às questões de cunho variacionista superficiais. Como podemos notar, há um acréscimo com relação ao resultado apresentado no gráfico 1, não obstante o resultado ainda se mostre muito tímido e aquém do desejado, ao levarmos em consideração a quantidade de questões disponíveis nas 40 provas analisadas do vestibular da UECE.

Assim, o gráfico 2 nos leva a um total de 2,68\% (18 questões) em que o fenômeno da variação linguística é contemplado em provas de vestibulares da UECE no período de 2009.2 a 2019.1 contra 97,32\% de outros assuntos linguísticos avaliados na disciplina de língua portuguesa. Esse resultado nos leva à conclusão de que é preciso refletir sobre a maneira como as provas de língua portuguesa do vestibular são elaboradas pela banca, pois, se levarmos em consideração que os $\mathrm{PCN}$ recomendam que o fenômeno da variação linguística deve ser matéria de discussão nos livros didáticos e em sala de aula, nada mais pertinente que esse fenômeno 
esteja presente de forma expressiva em provas de vestibulares e concursos, que selecionam alunos para entrar em instituições superior de ensino, sejam quais forem. Esse pensamento reflexivo se faz ainda necessário para a banca organizadora da UECE em específico, ao darmonos conta de que a variação linguística é um assunto contemplado na lista de conteúdos disponível nos editais, a fim de que os candidatos se preparem para o vestibular, conforme explicitamos na seção 3 deste artigo. Afirmamos isso porque, embora a banca não seja obrigada a explorar todos os conteúdos dispostos em edital, há uma incoerência em relação ao conteúdo programático e ao que realmente é avaliado nas provas, quando o assunto é variação linguística. Além do mais, apontamos tal incoerência ancorados no baixíssimo percentual de questões que contemplam esse fenômeno em uma amostra constituída por 40 provas com, ao todo, 670 questões de língua portuguesa.

Em seguida, expomos, por meio do gráfico 3, a disposição conjunta de questões dos tipos categórica e superficial tomando por base a fase do vestibular em que elas ocorreram.

Gráfico 3 - Questões categóricas e superficiais em relação à variação linguística nas provas de vestibular da UECE por fases

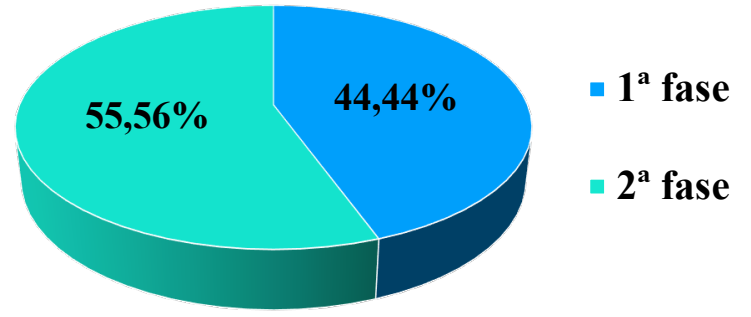

Fonte: elaborada pelos autores.

O gráfico 3 explana, por fim, o resultado para as questões selecionadas por contemplarem o fenômeno da variação linguística, comparando as fases em que foram aplicadas. Como podemos observar, as provas de segunda fase do vestibular apresentam uma quantidade maior de questões, 55,56\%, que contemplam o fenômeno da variação linguística, se comparadas às provas de primeira fase, 44,44\%. A diferença não é tão significativa, mas pode indicar que, na segunda fase da seleção, a banca dispõe de um maior espaço para avaliar os candidatos sobre esse fenômeno.

Na próxima seção, traçaremos nossas conclusões acerca da questão inicial: como o fenômeno da variação linguística se apresenta em provas do vestibular da UECE? 


\section{Considerações finais}

Esta pesquisa tornou possível fazermos considerações acerca do processo seletivo do vestibular da UECE no que diz respeito à presença, nas questões de língua portuguesa do certame, do fenômeno da variação linguística no português do Brasil.

Com base em nosso levantamento estatístico, identificamos que o número de questões de língua portuguesa dos vestibulares que abordavam outros assuntos era muito maior do que as que avaliavam o candidato quanto ao fenômeno da variação linguística; além de a porcentagem de questões com o conteúdo do variacionismo ser pequena, frisamos que nem todas elas cobravam integralmente o assunto (natureza categórica), uma vez que consideramos também aquelas que traziam esse conteúdo somente em distratores e/ou textos- -base (natureza superficial). Também constatamos que, comparando a quantidade de questões de natureza variacionista (categóricas e superficiais) por fases do vestibular, seu número era maior na segunda fase em relação à primeira, embora a diferença mostrou-se pouco significativa. Isso nos revelou que a banca elaboradora dispõe de mais espaço para avaliar o referido assunto nas questões da segunda fase, contudo a frequência é extremamente parca e não atende, portanto, às expectativas dos PCN no que tange ao conhecimento linguístico dos candidatos avaliados em relação ao fenômeno da variação linguística.

A partir dos resultados apresentados e discutidos, podemos concluir que, nos últimos dez anos (semestres 2009.2 a 2019.1), as provas de língua portuguesa do vestibular da UECE têm contido uma quantidade mínima de questões que avaliam os candidatos quanto ao fenômeno da variação linguística.

Esperamos, com este trabalho, além de motivar discussões atinentes à questão com vestibulares de outras instituições, contribuir para a melhoria das bancas organizadoras nos processos de elaboração das questões de língua portuguesa em seus certames. Afinal, entendemos que muito precisa ser feito no sentido de atender as recomendações dos PCN sobre o fenômeno da variação linguística.

\section{Referências}

BAGNO, Marcos. Nada na língua é por acaso: por uma pedagogia da variação linguística. São Paulo: Parábola Editorial, 2007.

BAGNO, Marcos. Sete erros aos quatro ventos: a variação linguística no ensino de português. São Paulo: Parábola editorial, 2013. 
BORTONI-RICARDO, Stella Maris. Educação em língua materna: a sociolinguística na sala de aula. São Paulo: Parábola, 2004

BRASIL. Secretaria de Educação Fundamental. Parâmetros Curriculares Nacionais: língua portuguesa. Brasília: MEC, 1997

CALVET, Loiuis-Jean. Sociolinguística: uma introdução crítica. Tradução de Marcos Marciolino. São Paulo: Parábola Editorial, 2002.

CAMACHO, Roberto Gomes. Sociolinguística. In: MUSSALIM, Fernanda; BENTES, Anna Christina. (Org.). Introdução à linguística: domínios e fronteiras. vol. 1. 9. ed. São Paulo: Cortez, 2012. p. 51-83.

COELHO, Paula Maria Cobucci Ribeiro. O tratamento da variação linguística nos livros didáticos de português. 2007. 151 f. Dissertação (Mestrado em Linguística) - Programa de Pós-Graduação em Linguística, Universidade de Brasília, Brasília-DF, $2007 . \quad$ Disponível em: $<$ https://core.ac.uk/download/pdf/33531509.pdf>. Acesso em: 17 mar. 2019.

COMISSÃO EXECUTIVA DO VESTIBULAR (CEV/UECE). Manual do Candidato: Vestibular 2019.1. Fortaleza, 2018. 42 p. Disponível em: <http://uece.br/cev/index.php/vestibular-20191>. Acesso em: 28 fev. 2019.

FARACO, Carlos Alberto. Norma culta brasileira: desembaraçando alguns nós. São Paulo: Parábola Editorial, 2015.

FONSECA, João José Saraiva. Metodologia da pesquisa científica. Fortaleza: UECE, 2002.

GORSKI, Edair Maria; COELHO, Izete Lehmkuhl. (Org.). Sociolinguística e ensino: contribuições para a formação do professor de língua. Florianópolis: Ed. Da UFSC, 2006.

LABOV, William. Padrões sociolinguísticos. Tradução de Marcos Bagno, Maria Marta Pereira Scherre, Caroline Rodrigues Cardoso. São Paulo: Parábola Editorial, 2008.

TARALLO, Fernando Luiz. A pesquisa sociolinguística. 8. ed. São Paulo: Ática, 2007.

TRIVIÑOS, Augusto Nibaldo Silva. Introdução à pesquisa em ciências sociais: a pesquisa qualitativa em educação. São Paulo: Atlas, 1987.

VOTRE, Sebastião José. Relevância da variável escolaridade. In: MOLLICA, Maria Cecília; BRAGA, Maria Luiza (Org.). Introdução à sociolinguística: o tratamento da variação. São Paulo: Contexto, 2003. p. 51-57.

WEINREICH, Uriel; LABOV, William; HERZOG, Marvin I. Fundamentos empíricos para uma teoria da mudança linguística. Tradução Marcos Bagno. São Paulo: Parábola Editorial, 2006. 